\title{
Effect of dexmedetomidine on brain function and hemodynamics in patients undergoing lung cancer resection
}

\author{
YUNFENG LI ${ }^{1}, \mathrm{CHUNYU}_{\text {WANG }}{ }^{2}, \mathrm{MINGZHUANG} \mathrm{BI}^{3}$, \\ $\mathrm{JIE} \mathrm{GAO}^{4}, \mathrm{XUE} \mathrm{ZHANG}^{4}$ and HAITAO TIAN ${ }^{5-7}$ \\ ${ }^{1}$ Department of Pharmacy, Weifang People's Hospital, Weifang, Shandong 261041; \\ ${ }^{2}$ Department of Anesthesiology, Qingdao Eighth People's Hospital, Qingdao, Shandong 266100; \\ ${ }^{3}$ Department of Anesthesiology, Qingdao Women and Children's Hospital, Qingdao, Shandong 266034; \\ ${ }^{4}$ Department of Anesthesiology, The Affiliated Hospital of Qingdao University, Qingdao, Shandong 266000; \\ ${ }^{5}$ Department of Anesthesiology, Jining No. 1 People's Hospital; ${ }^{6}$ Department of Anesthesiology, \\ Affiliated Jining No. 1 People's Hospital of Jining Medical University; \\ ${ }^{7}$ Jining Medical University, Jining, Shandong 272000, P.R. China
}

Received November 26, 2019; Accepted December 20, 2019

DOI: $10.3892 / \mathrm{ol} .2020 .11675$

\begin{abstract}
Effect of dexmedetomidine on the brain function and hemodynamics in patients undergoing lung cancer resection were explored. Eighty-seven patients with lung cancer undergoing lung cancer resection in Weifang People's Hospital from January 2014 to June 2018 were enrolled in this study. Patients conventionally anesthetized by propofol, midazolam, sufentanil, or cisatracurium besilate (41 cases) were assigned to the control group and those anesthetized by conventional anesthetic and dexmedetomidine (46 cases) were assigned to the research group. The hemodynamic parameters, neuron-specific enolase (NSE), and astrocyte $\mathrm{S}-100 \mathrm{p}$ protein $(\mathrm{S}-100 \beta)$ were compared between the two groups before induction (T0), 5 min after induction (T1), at the end of surgery (T2), time of extubation (T3), and 5 min after extubation (T4). The cognitive function of patients was graded by the mini-mental state examination (MMSE) after patients recovered from anesthesia. In both the control group and the research group, the levels of mean arterial pressure (MAP), heart rate (HR), and central venous pressure (CVP). were statistically higher at T2 and T3 than those at T0 (all $\mathrm{P}<0.05$ ). The levels of MAP, HR, and CVP were statistically lower in the research group than those in the control group at T2 and T3 $(\mathrm{P}<0.05)$. The levels of serum NSE and $\mathrm{S} 100 \beta$ protein in the research group and the control group
\end{abstract}

Correspondence to: Dr Haitao Tian, Department of Anesthesiology, Jining No. 1 People's Hospital, 6 Jiankang Road, Jining, Shandong 272000, P.R. China

E-mail:vgd07v@163.com

Key words: dexmedetomidine, lung cancer, brain function, hemodynamics, cognitive function increased at T2, T3, and T4, the control group was higher than the research group at each time point, and the difference was statistically significant $(\mathrm{P}<0.05)$. Comparison of the MMSE score and the total case number of adverse reactions between the two groups showed no statistical difference (both $\mathrm{P}>0.05$ ). The MMSE score was positively correlated with the serum levels of NSE and S100 $\beta$ in the two groups (r-values were 0.661 and $0.585, \mathrm{P}<0.05$ ). Dexmedetomidine can effectively protect patients' perioperative brain function with small impacts on perioperative hemodynamics, so it is worthy of clinical application.

\section{Introduction}

Lung cancer is a malignant tumor that seriously threatens human health. In recent years, China has seen a simultaneous year-on-year increase in the number of lung cancer patients and the mortality (1). Lung cancer is the leading cause of death from cancer, the principal factor for cancer death in men, and the second cancer killer of women (2).

Advancements in science and technology have significantly improved the early diagnosis rate of lung cancer. Surgery is the preferred treatment for most patients, but the anesthesia and surgical trauma often cause a stress response. Trauma or surgical injury can activate immune inflammation and neuroendocrine reactions, leading to ischemic brain damage (3). The subsequent destruction of the blood-brain barrier causes brain dysfunction, leading to postoperative cognitive dysfunction (POCD) (4). As the main complication that contributes to disability and distress in millions of patients every year (5), POCD results in prolonged hospital stay, weakened physical functions, and increased mortality $(6,7)$, which severely damages the prognosis and quality of life of patients. So the rational use of anesthetic drugs is crucial for the treatment and prognosis of patients. 
Table I. Comparison of basic information.

\begin{tabular}{|c|c|c|c|c|}
\hline Factors & Research group $(\mathrm{n}=41)$ & Control group $(n=46)$ & $t / \chi^{2}$ & P-value \\
\hline Age (year) & $67.37 \pm 3.27$ & $67.26 \pm 2.07$ & 0.190 & 0.850 \\
\hline $\mathrm{B} \backslash \mathrm{I}\left(\mathrm{kg} / \mathrm{m}^{2}\right)$ & $21.3 \pm 2.45$ & $21.5 \pm 2.36$ & 0.388 & 0.699 \\
\hline \multicolumn{5}{|l|}{ Sex } \\
\hline Male & $21(51.22)$ & $24(52.17)$ & & \\
\hline Female & $20(48.78)$ & $22(47.83)$ & 0.008 & 0.939 \\
\hline \multicolumn{5}{|c|}{ Hypertension } \\
\hline Yes & $18(43.90)$ & $20(43.48)$ & & \\
\hline No & $23(56.10)$ & $26(56.52)$ & 0.002 & 0.968 \\
\hline \multicolumn{5}{|l|}{ Diabetes } \\
\hline Yes & $19(46.34)$ & $21(45.65)$ & & \\
\hline No & $22(53.66)$ & $25(54.35)$ & 0.004 & 0.949 \\
\hline \multicolumn{5}{|c|}{ Hyperlipemia } \\
\hline Yes & $20(48.78)$ & $24(52.17)$ & & \\
\hline No & $21(51.22)$ & $22(47.83)$ & 0.099 & 0.752 \\
\hline \multicolumn{5}{|l|}{ Smoking } \\
\hline Yes & $28(68.29)$ & $27(58.70)$ & & \\
\hline No & $13(31.71)$ & $19(41.30)$ & 0.859 & 0.354 \\
\hline \multicolumn{5}{|l|}{ Drinking } \\
\hline Yes & $25(60.98)$ & $26(56.52)$ & & \\
\hline No & $16(39.02)$ & $20(43.48)$ & 0.177 & 0.673 \\
\hline
\end{tabular}

Dexmedetomidine is an $\alpha-2$ adrenergic receptor agonist with sedative and analgesic effects, widely used for general anesthesia (8). Extubation during surgery can induce hemodynamic changes. Studies have reported that $(9,10)$ dexmedetomidine has a biphasic hemodynamic effect. It can regulate the release of norepinephrine and inhibit sympathetic activity, thereby reducing the release of inflammatory factors and stabilizing blood pressure. Dexmedetomidine can reduce the risk of hypertension and tachycardia in neurosurgical patients $(11,12)$ and is widely used clinically.

So far, there have been few reports on the effects of dexmedetomidine on brain function and hemodynamics in patients with lung cancer resection. Therefore, this study assessed the cognitive function and hemodynamic parameters in patients receiving dexmedetomidine anesthesia.

\section{Patients and methods}

Basic patient information. Eighty-seven patients with lung cancer undergoing lung cancer resection in Weifang People's Hospital (Weifang, China) from January 2014 to June 2018 were enrolled in this study. There were 41 patients undergoing conventional anesthesia in the control group and 46 patients undergoing conventional anesthesia and dexmedetomidine anesthesia in the research group. The two groups were not notably different regarding age, sex, and other basic information.

Inclusion criteria: Patients diagnosed with lung cancer and willing to receive surgical resection; patients not treated with radiotherapy or chemotherapy before; patients with no other malignant tumors. Exclusion criteria: Patients with liver and kidney dysfunction or communicative and cognitive impairment; patients who did not cooperate with the experiment. All patients and their families agreed to participate in the experiment and signed an informed consent form. This study was approved by the Ethics Committee of the hospital.

Methods. The venous access was established at the beginning of the operation and the basic vital signs of patients were under close monitoring. In this study, propofol, midazolam, sufentanil, and cisatracurium besilate were used for conventional anesthesia. Patients in the control group underwent conventional anesthesia, while patients in the research group underwent conventional anesthesia and dexmedetomidine anesthesia (Sinopharm Group Guorui Medicine Co., Ltd.) through intravenous injection at an initial dose of $0.5 \mu \mathrm{g} / \mathrm{kg}$ and then at a fixed dose of $0.1 \mu \mathrm{g} / \mathrm{kg}-1 \mathrm{~h}-1$. Elbow venous blood $(5 \mathrm{ml})$ was drawn from all patients at T0, T1, T2, T3, and T4, respectively, and then centrifuged at $1,500 \mathrm{x}$ and $4^{\circ} \mathrm{C}$ for $10 \mathrm{~min}$. Then the supernatant was collected and placed at $-80^{\circ} \mathrm{C}$ in a refrigerator for later use. The expression levels of neuron-specific enolase (NSE) and S-100 $\beta$ in the serum of the patients were determined by enzyme-linked immunosorbent assay (ELISA) in strict accordance with the kit manuals. All kits were from Shanghai Guangrui Biological Co., Ltd.

Outcome measures. a) Hemodynamic parameters at different time points in the two groups: mean arterial pressure (MAP), heart rate (HR), and central venous pressure (CVP). b) Expression levels of NSE and S-100 $\beta$ at different time 
Table II. Hemodynamic parameters at different time points in the two groups.

\begin{tabular}{lllll}
\hline Group & Time & MAP $/ \mathrm{kPa}$ & HR (beat/min) & CVP $(\mathrm{mmHg})$ \\
\hline Research group $(\mathrm{n}=41)$ & T0 & $10.2 \pm 1.6$ & $82.61 \pm 7.34$ & $88.61 \pm 5.25$ \\
& T1 & $10.4 \pm 1.4$ & $81.60 \pm 7.35$ & $87.61 \pm 5.35$ \\
& T2 & $11.0 \pm 1.5^{\mathrm{a}, \mathrm{b}, \mathrm{e}}$ & $85.37 \pm 8.35^{\mathrm{a}, \mathrm{b}, \mathrm{e}}$ & $91.61 \pm 6.25^{\mathrm{a}, \mathrm{b}, \mathrm{e}}$ \\
& T3 & $11.4 \pm 1.4^{\mathrm{a}, \mathrm{b}, \mathrm{e}}$ & $88.61 \pm 8.25^{\mathrm{a}, \mathrm{b}, \mathrm{e}}$ & $93.61 \pm 6.35^{\mathrm{a}, \mathrm{b}, \mathrm{e}}$ \\
& T4 & $10.3 \pm 1.3^{\mathrm{c}, \mathrm{d}}$ & $83.60 \pm 7.34^{\mathrm{c}, \mathrm{d}}$ & $86.61 \pm 5.45^{\mathrm{c}, \mathrm{d}}$ \\
Control group $(\mathrm{n}=46)$ & T0 & $10.4 \pm 1.2$ & $81.95 \pm 8.43$ & $87.61 \pm 5.23$ \\
& T1 & $10.5 \pm 1.3$ & $80.95 \pm 8.43$ & $88.61 \pm 5.35$ \\
& T2 & $11.8 \pm 1.6^{\mathrm{a}, \mathrm{b}}$ & $95.38 \pm 7.68^{\mathrm{a}, \mathrm{b}}$ & $95.61 \pm 6.53^{\mathrm{a}, \mathrm{b}}$ \\
& T3 & $12.4 \pm 1.5^{\mathrm{a}, \mathrm{b}}$ & $97.38 \pm 7.58^{\mathrm{a}, \mathrm{b}}$ & $87.61 \pm 6.46^{\mathrm{a}, \mathrm{b}}$ \\
\hline
\end{tabular}

${ }^{\mathrm{a}} \mathrm{P}<0.05$ when compared with $\mathrm{T} 0$ within the group; ${ }^{\mathrm{b}} \mathrm{P}<0.05$ when compared with $\mathrm{T} 1$ within the group; ${ }^{\mathrm{c}} \mathrm{P}<0.05$ when compared with $\mathrm{T} 2$ within the group; ${ }^{\mathrm{P}}<0.05$ when compared with $\mathrm{T} 3$ within the group; ${ }^{\mathrm{e}} \mathrm{P}<0.05$ when compared with $\mathrm{T} 4$ within the group. MAP, mean arterial pressure; $\mathrm{HR}$, heart rate; CVP, central venous pressure.

Table III. Expression levels of serum NSE and S100 $\beta$ at different time points in the two groups.

\begin{tabular}{|c|c|c|c|}
\hline Group & Time & $\mathrm{NSE}(\mu \mathrm{g} / \mathrm{l})$ & $\mathrm{S} 100 \beta(\mu \mathrm{g} / 1)$ \\
\hline \multirow[t]{5}{*}{ Research group $(n=41)$} & $\mathrm{T} 0$ & $0.14 \pm 0.03$ & $5.67 \pm 1.56$ \\
\hline & $\mathrm{T} 1$ & $0.15 \pm 0.04$ & $5.72 \pm 1.62$ \\
\hline & $\mathrm{T} 2$ & $0.76 \pm 0.13^{\mathrm{a}, \mathrm{b}, \mathrm{e}}$ & $6.62 \pm 1.78^{\mathrm{a}, \mathrm{b}, \mathrm{e}}$ \\
\hline & $\mathrm{T} 3$ & $0.82 \pm 0.18^{\mathrm{a}, \mathrm{b}, \mathrm{e}}$ & $6.89 \pm 1.93^{\mathrm{a}, \mathrm{b}, \mathrm{e}}$ \\
\hline & $\mathrm{T} 4$ & $0.98 \pm 0.21^{\mathrm{a}-\mathrm{e}}$ & $7.79 \pm 1.98^{\mathrm{a}-\mathrm{e}}$ \\
\hline \multirow[t]{5}{*}{ Control group $(n=46)$} & $\mathrm{T} 0$ & $0.13 \pm 0.03$ & $5.68 \pm 1.46$ \\
\hline & $\mathrm{T} 1$ & $0.15 \pm 0.05$ & $5.82 \pm 1.36$ \\
\hline & $\mathrm{T} 2$ & $1.26 \pm 0.13^{\mathrm{a}, \mathrm{b}}$ & $8.67 \pm 1.16^{\mathrm{a}, \mathrm{b}}$ \\
\hline & $\mathrm{T} 3$ & $1.30 \pm 0.12^{\mathrm{a}, \mathrm{b}}$ & $8.87 \pm 1.26^{\mathrm{a}, \mathrm{b}}$ \\
\hline & $\mathrm{T} 4$ & $1.43 \pm 0.15^{\mathrm{a}-\mathrm{d}}$ & $9.37 \pm 1.36^{\mathrm{a}-\mathrm{d}}$ \\
\hline
\end{tabular}

${ }^{\mathrm{a}} \mathrm{P}<0.05$ when compared with $\mathrm{T} 0$ within the group; ${ }^{\mathrm{b}}<0.05$ when compared with $\mathrm{T} 1$ within the group; ${ }^{\mathrm{P}}<0.05$ when compared with $\mathrm{T} 2$ within the group; ${ }^{\mathrm{d}} \mathrm{P}<0.05$ when compared with $\mathrm{T} 3$ within the group; ${ }^{\mathrm{e}} \mathrm{P}<0.05$ when compared with $\mathrm{T} 4$ within the group. NSE, neuron-specific enolase.

points in the two groups. c) Cognitive function indicated by the mini-mental state examination (MMSE) score in the two groups before the anesthesia and after the recovery from anesthesia. d) The case number of adverse reactions in the two groups. e) Correlation analysis between MMSE scores and serum NSE and S100 $\beta$ levels in the two groups.

Statistical analysis. Statistical analysis was performed on SPSS 20.0 software. The measurement data were expressed as the mean \pm standard deviation (mean \pm SD). t-test was used for intergroup comparison and paired t-test was used for intra-group comparison. The count data were expressed by $\mathrm{n} / \%$ and intergroup comparison was performed by the $\chi^{2}$ test. Correlation analysis was performed using the Spearman correlation coefficient. The difference was considered statistically significant at $\mathrm{P}<0.05$.

\section{Results}

Comparison of the basic information between the two group. The two groups were not statistically different in age, BMI, and other basic information ( $\mathrm{P}>0.05)$ (Table I).

Hemodynamic parameters at different time points in the two groups. In both the control group and the research group, the levels of MAP, HR, and CVP were statistically higher at T2 and T3 than those at T0 (all P<0.05). The levels of MAP, HR, and CVP were statistically lower in the research group than those in the control group at T2 and T3 $(\mathrm{P}<0.05)$ (Table II).

The expression levels of serum NSE and S100 $\beta$ at different time points in the two groups. The levels of serum NSE and $\mathrm{S} 100 \beta$ protein in the research group and the control group 
Table IV. MMSE scores in the two groups before the anesthesia and after the recovery from anesthesia.

\begin{tabular}{lccr}
\hline Group & Research group $(\mathrm{n}=41)$ & Control group $(\mathrm{n}=46)$ & $\mathrm{t}$ \\
\hline Before the anesthesia & $28.54 \pm 4.34$ & $28.48 \pm 4.25$ & 0.065 \\
After the recovery from anesthesia & $27.34 \pm 2.45$ & $27.21 \pm 3.11$ & 0.948 \\
\hline
\end{tabular}

MMSE, mini-mental state examination.

Table V. Case number of adverse reactions in the two groups.

\begin{tabular}{|c|c|c|c|c|}
\hline Group & Research group $(n=41)$ & Control group $(n=46)$ & $\chi^{2}$ & P-value \\
\hline Hypotension & $1(2.44)$ & $1(2.17)$ & 0.007 & 0.934 \\
\hline Sinus bradycardia & $1(2.44)$ & $2(4.35)$ & 0.237 & 0.626 \\
\hline Sinus tachycardia & 0 & $2(4.35)$ & 1.825 & 0.177 \\
\hline Total number of adverse reactions & $2(4.88)$ & $5(10.87)$ & 1.052 & 0.305 \\
\hline
\end{tabular}
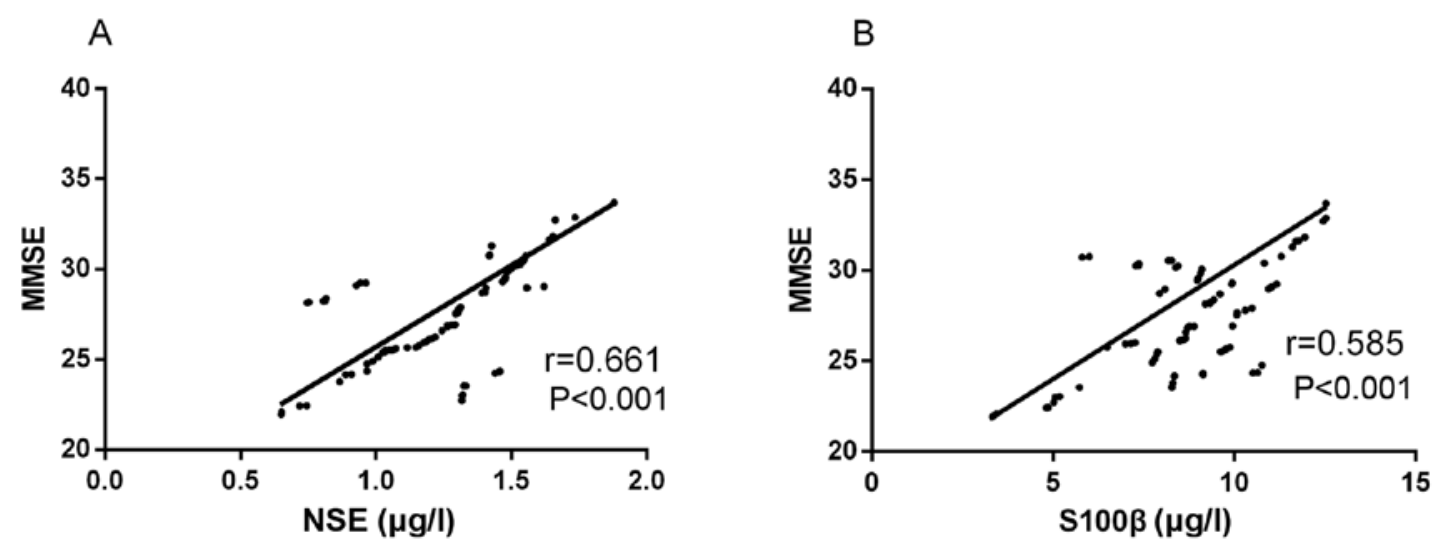

Figure 1. Correlation analysis between MMSE scores and serum NSE and S100 $\beta$ levels. (A) MMSE scores were positively correlated with NSE levels in the two groups $(r=0.661, \mathrm{P}<0.001)$. (B) MMSE scores were positively correlated with $\mathrm{S}-100 \beta$ levels in the two groups $(\mathrm{r}=0.585$, $\mathrm{P}<0.001)$. MMSE, mini-mental state examination; NSE, neuron-specific enolase.

increased at T2, T3, and T4, higher in control group than those in the research group at each time point, and the difference was statistically significant $(\mathrm{P}<0.05)$ (Table III).

MMSE scores in the two groups before the anesthesia and after the recovery from anesthesia. The comparison of MMSE scores before anesthesia and after recovery from anesthesia showed no statistical difference between the two groups (P>0.05) (Table IV).

Case number of adverse reactions in the two groups. One case of hypotension and 1 case of sinus bradycardia were reported in the research group, while 1 case of hypotension, 2 cases of sinus bradycardia, and 2 cases of sinus tachycardia were reported in the control group. The two groups were not statistically different in the total number of adverse reactions $(\mathrm{P}>0.05)$ (Table V).

Correlation analysis between MMSE scores and serum NSE and S100 $\beta$ levels. The MMSE scores of the two groups were positively correlated with the expression levels of serum NSE and S100 $\beta$ (P<0.001) (Fig. 1).

\section{Discussion}

Good anesthesia can increase the success rate of surgery, reduce intraoperative inflammation and stress response, and improve the prognosis and recovery of postoperative organ function (13). Dexmedetomidine can inhibit neuronal discharge to achieve resistance to anxiety, suppress sympathetic nerve activity, reduce neuronal apoptosis, and alleviate the body's inflammatory response (3). Lung cancer resection, a common surgery for lung cancer treatment, leads to high risk of POCD in patients, which manifests as insanity, anxiety, and personality changes. These complications may be associated with factors such as anesthesia methods, types of surgery, and cognitive differences (14). Elderly patients general have other organ diseases such as cardiovascular disease, which will increase the risk of intubation. Therefore, monitoring the 
patient's hemodynamics and maintaining its stability is also important during the surgical anesthesia. This study aimed to explore the effect of dexmedetomidine on the brain function and hemodynamics in patients undergoing lung cancer resection.

In our study, MAP, HR, and CVP levels were significantly increased at T2 and T3 in both the control group and the research group, with higher levels in the research group, suggesting that the control group underwent great hemodynamic fluctuations, while dexmedetomidine effectively maintained the hemodynamic stability in the research group. The reason why dexmedetomidine contributes to hemodynamic stability may be that dexmedetomidine is involved in the systemic circulation so as to achieve sedation and analgesia and suppress the sympathetic nervous system activity. A previous study (15) reported that dexmedetomidine stabilized the hemodynamics of patients undergoing head and neck reconstruction. Another study (16) stated that intraoperative dexmedetomidine could better control postoperative MAP and provide a better analgesic effect for patients with craniotomy, which is consistent with the results of this study.

NSE is a highly specific marker for neuronal and peripheral neuroendocrine cells. When NSE is found in specific tissues under normal conditions, its increased body fluid levels may be accompanied by malignant proliferation and thus be valuable in the diagnosis, staging, and treatment of neuroendocrine tumors $(17,18)$. S100B is a calcium-binding protein found mainly in mature perivascular astrocyte cytoplasms (19). S100B protein and NSE are the most studied serum markers in the field of brain injury (20). In this study, serum expression levels of NSE and S100 $\beta$ were increased at T2, T3, and T4 in the research group and the control group. Serum expression levels of NSE and S100 $\beta$ protein were higher in the control group than those in the research group at each time point, and the MMSE scores of the two groups were positively correlated with the expression levels of NSE and S100 $\beta$, suggesting that the severity of cognitive impairment was positively correlated with the expression levels of NSE and S100 $\beta$. So we speculate that the expression levels of NSE and $\mathrm{S} 100 \beta$ can be used to monitor the postoperative cognitive impairment in patients. The study by Zhang et al (21) found that the increase in serum NSE and S100- $\beta$ levels was correlated with the occurrence of cognitive impairment in patients with brain injury. Chaves et al (22) considered that higher S100 $\beta$ protein levels led to worse cognitive function, higher NSE level, and more severe brain atrophy. Therefore, the use of dexmedetomidine before anesthesia induction can reduce serum NSE and S100- $\beta$ protein levels and improve the stability of cognitive functions in patients. No marked difference was shown in the total case number of adverse reactions and MMSE scores between the two groups before the anesthesia and after the recovery from anesthesia, indicating that dexmedetomidine is safe and worthy of clinical application and promotion.

In conclusion, the use of dexmedetomidine before the anesthesia induction can stabilize the hemodynamic parameters and certainly protect the brain function. However, the results of this study need to be further verified due to the small sample size.

\section{Acknowledgements}

Not applicable.

\section{Funding}

Key Research and Development Projects in Shandong (2018GSF118216); Development Plan of Medical and Health Science and Technology Projects in Shandong province (2017WS524).

\section{Availability of data and materials}

The datasets used and/or analyzed during the present study are available from the corresponding author on reasonable request.

\section{Authors' contributions}

YL, CW, MB and HT led the conception and design of this study. YL, CW, JG, XZ and HT were responsible for the data collection and analysis. YL, MB and JG were in charge of interpreting the data and drafting the manuscript. $\mathrm{CW}$ and $\mathrm{HT}$ made revision from critical perspective for important intellectual content. The final version was read and adopted by all the authors.

\section{Ethics approval and consent to participate}

The study was approved by the Ethics Committee of Weifang People's Hospital (Weifang, China). Signed informed consents were obtained from the patients and/or the guardians.

\section{Patient consent for publication}

Not applicable.

\section{Competing interests}

The authors declare that they have no competing interests.

\section{References}

1. Zhang Y, Zheng T and Zhang W: Report of cancer incidence and mortality in China, 2012. Adv Mod Oncol Res 4: 1-7, 2018.

2. Torre LA, Siegel RL and Jemal A: Lung cancer statistics. In: Lung Cancer and Personalized Medicine. Springer, Cham. Adv Exp Med Biol 893: 1-19, 2016

3. Jiang L, Hu M, Lu Y, Cao Y, Chang Y and Dai Z: The protective effects of dexmedetomidine on ischemic brain injury: A meta-analysis. J Clin Anesth 40: 25-32, 2017.

4. Hudetz JA, Patterson KM, Iqbal Z, Gandhi SD and Pagel PS: Remote ischemic preconditioning prevents deterioration of short-term postoperative cognitive function after cardiac surgery using cardiopulmonary bypass: Results of a pilot investigation. J Cardiothorac Vasc Anesth 29: 382-388, 2015

5. Müller A, Lachmann G, Wolf A, Mörgeli R, Weiss B and Spies C: Peri- and postoperative cognitive and consecutive functional problems of elderly patients. Curr Opin Crit Care 22: 406-411, 2016.

6. Brown CH IV, Laflam A, Max L, Lymar D, Neufeld KJ, Tian J, Shah AS, Whitman GJ and Hogue CW: The impact of delirium after cardiac surgical procedures on postoperative resource use. Ann Thorac Surg 101: 1663-1669, 2016.

7. Monk TG, Saini V, Weldon BC and Sigl JC: Anesthetic management and one-year mortality after noncardiac surgery. Anesth Analg 100: 4-10, 2005. 
8. Li A, Yuen VM, Goulay-Dufay S and Kwok PC: Pharmacokinetics and pharmacodynamics of dexmedetomidine. Drug Dev Ind Pharm 42: 1917-1927, 2016.

9. Bloor BC, Ward DS, Belleville JP and Maze M: Effects of intravenous dexmedetomidine in humans. II. Hemodynamic changes. Anesthesiology 77: 1134-1142, 1992.

10. Gertler R, Brown HC, Mitchell DH and Silvius EN: Dexmedetomidine: A novel sedative-analgesic agent. Proc Bayl Univ Med Cent 14: 13-21, 2001.

11. Tanskanen PE, Kyttä JV, Randell TT and Aantaa RE: Dexmedetomidine as an anaesthetic adjuvant in patients undergoing intracranial tumour surgery: A double-blind, randomized and placebo-controlled study. Br J Anaesth 97: 658-665, 2006

12. Bekker A, Sturaitis M, Bloom M, Moric M, Golfinos J, Parker E, Babu R and Pitti A: The effect of dexmedetomidine on perioperative hemodynamics in patients undergoing craniotomy. Anesth Analg 107: 1340-1347, 2008.

13. Yao ZY, Jia Z, Xie YH, Zhang LL, Zhang HS, Wu WQ, Zhang CK and Gan LJ: Analgesic effect of dezocine in different doses on elderly patients undergoing abdominal operation under general anesthesia and its influence on stress response to postoperative tracheal extubation. Eur Rev Med Pharmacol Sci 21: 5223-5229, 2017.

14. Kunnimalaiyaan S, Sokolowski KM, Balamurugan M, Gamblin TC and Kunnimalaiyaan M: Xanthohumol inhibits Notch signaling and induces apoptosis in hepatocellular carcinoma. PLoS One 10: e0127464, 2015.

15. Rajan S, Moorthy S, Paul J and Kumar L: Effect of dexmedetomidine on postoperative hemodynamics and outcome of free flaps in head and neck reconstructive surgeries. Open Anesthesiol J 10: 10, 2016.
16. Rajan S, Hutcherson MT, Sessler DI, Kurz A, Yang D, Ghobrial M, Liu J and Avitsian R: The effects of dexmedetomidine and remifentanil on hemodynamic stability and analgesic requirement after craniotomy: a randomized controlled trial. J Neurosurg Anesthesiol 28: 282-290, 2016.

17. Isgrò MA, Bottoni $\mathrm{P}$ and Scatena R: Neuron-specific enolase as a biomarker: Biochemical and clinical aspects. In: Advances in Cancer Biomarkers. Scatena R (ed). Springer, Dordrecht. Adv Exp Med Biol 867: 125-143, 2015.

18. Haque A, Ray SK, Cox A and Banik NL: Neuron specific enolase: A promising therapeutic target in acute spinal cord injury. Metab Brain Dis 31: 487-495, 2016.

19. Donato R, Sorci G, Riuzzi F, Arcuri C, Bianchi R, Brozzi F, Tubaro C and Giambanco I: S100B's double life: Intracellular regulator and extracellular signal. Biochim Biophys Acta 1793: 1008-1022, 2009.

20. Yokobori S, Hosein K, Burks S, Sharma I, Gajavelli S and Bullock R: Biomarkers for the clinical differential diagnosis in traumatic brain injury - a systematic review. CNS Neurosci Ther 19: 556-565, 2013.

21. Zhang Y, Junfang MA and Meng Y: Changes of serum neuron specific enolase and S100- $\beta$ protein and their correlations with cognitive impairment in patients with moderate traumatic brain injury. Chin J Traumatol 33: 886-889, 2017.

22. Chaves ML, Camozzato AL, Ferreira ED, Piazenski I, Kochhann R, Dall'Igna O, Mazzini GS and Souza DO and Portela LV: Serum levels of S100B and NSE proteins in Alzheimer's disease patients. J Neuroinflammation 27: 76, 2010. Attribution-NonCommercial-NoDerivatives 4.0 International (CC BY-NC-ND 4.0) License. 